\title{
Mulheres em um mundo de homens: representação feminina em Narcos e a ilusão da ficção seriada "universal"
}

\author{
Marina Soler Jorge ${ }^{1}$ (iD 0000-0002-3352-7509 \\ 'Universidade Federal de São Paulo, Guarulhos, SP, Brasil. \\ 07252-312 - unifesp@unifesp.br
}

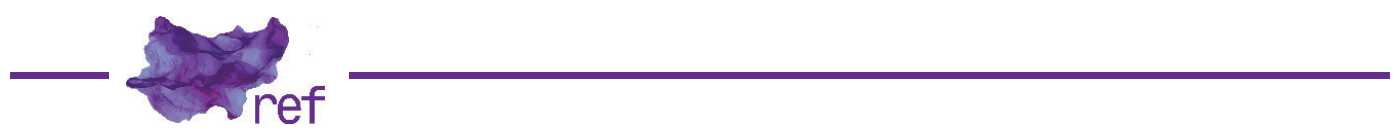

Resumo: Neste artigo temos como objetivo analisar o tratamento conferido a personagens femininos em uma narco-narrativa contemporânea, a terceira temporada de Narcos. Nosso problema de investigação é a compreensão das representações femininas em produtos altamente consumidos e que, sob uma estética aparentemente "neutra", internacional, profi ssional, dirigida a um amplo espectro de consumidores "exigentes", da visibilidade, sobretudo a uma parcela masculina da sociedade. Pretendemos entender, portanto, a partir de um estudo de caso, de que modo, sob a aparência da universalidade, a đição seriada corrobora a manutenção da sub-representação feminina.

Palavras-chave: Narco-narrativas; representação feminina; mulheres latino-americanas.

Women in a World of Men: Female Representation in Narcos and the Illusion of "Universal" Serial Fiction

Abstract: TThis article analyzes the treatment of female characters in a contemporary narconarrative, the third season of Narcos. Our research problem is to understand female representation in highly consumed products which, under a seemingly "neutral", international, professional aesthetic, directed at a wide spectrum of "demanding" consumers, mainly give visibilty to male characteres. We use a case study to understand how, under the guise of universality, serial fiction maintains female underrepresentation.

Keywords: Narco-narrative; female representation; Latin-American women.

No audiovisual contemporâneo, as ficções seriadas, ou séries, têm ocupado um lugar importante, tanto no que se refere à recepção crítica quanto ao público que têm alcançado. Enquanto a Netflix se consolida como produtora e distribuidora de conteúdo via streaming, TVs a cabo tradicionais como a HBO procuram modernizar seus aplicativos para dispositivos móveis e novos setores, como a Amazon, entram no mercado. Na imprensa tradicional, a cobertura de cinema inevitavelmente cede espaço a reviews de novas séries e temporadas, enquanto todo um setor da crítica passa a ser dominado por youtubers e twiteiros que exibem o que poderíamos considerar como uma erudição aplicada à cultura de massas, assistindo aos capítulos inúmeras vezes e analisando seus aspectos formais.

Nos últimos anos, podemos observar que séries de temática feminina (e feminista) criam grande entusiasmo entre os espectadores, como The Handmaid's Tale (2017-) e Big Little Lies (2017-2019). Séries de gêneros tradicionalmente masculinos, de faroeste, fantasia ou ficção, ou como Godless (2017), Game of Thrones (2011-2019) e Westworld (2016-), desenvolvem fortes personagens femininos, culminando com uma guerra entre rainhas no segundo exemplo e uma rebelião comandada por mulheres no terceiro. Do ponto de vista da produção, mulheres ganham mais espaço nas equipes realizadoras, para além das funções tradicionais de figurinistas, e atuam como diretoras e showrunners - a exemplo de Lisa Joy, que divide com Jonathan Nolan a produção da citada Westworld, e Shonda Rhimes, responsável por Grey's Anatomy (2005-) e 
How to get away with murder (2014-). Como a maior parte da indústria do entretenimento, no entanto, o segmento é dominado por homens. A ReFrame, organização estadunidense que avalia a diversidade de gênero representada no cinema e na televisão, constatou que, em 2018, apenas duas em cada dez séries analisadas incluem quantidade significativa de mulheres entre seus personagens e equipe de produção. O universo das séries constitui-se como um espaço importante, simbólica, política, e culturalmente, na contemporaneidade, que ainda resta a ser ocupado por mulheres, ainda que possamos vislumbrar algumas mudanças recentes, conquistadas graças aos esforços de artistas e ativistas.

Tão importante quanto qualificar e quantificar a participação das mulheres no entretenimento audiovisual contemporâneo é entender de que modo se constrói uma ideologia que visa caracterizar as séries como produtos opostos às antigas fórmulas narrativas televisivas, tratadas como menos sofisticadas. No livro Homens Difíceis, por exemplo, Brett Martin (2014) analisa o impacto recente das séries contemporâneas criando uma narrativa teórica que dá protagonismo total aos homens, sejam personagens, atores ou showrunners. Há, na obra, o que poderíamos considerar um gozo ao lidar com a personalidade complicada, extravagante e imprevisível dos homens envolvidos no mercado de séries. Como de costume na sociedade patriarcal, as extravagâncias de atores e showrunners, quando associadas ao sexo masculino, são vistas como uma espécie de charme especial inegavelmente ligado ao talento. Essas características são transferidas aos personagens das séries, cujo sucesso é atribuído a suas idiossincrasias. Um dos entrevistados do livro conta o que aprendeu sobre os heróis das séries: "[o herói] pode fazer um monte de coisas ruins, pode cometer todo tipo de erro, pode ser preguiçoso e parecer idiota, desde que seja o mais esperto de todos e faça bem o seu trabalho" (apud MARTIN, 2014, p. 63). Perguntamos-nos se uma heroína se beneficiaria da mesma indulgência ou se seria classificada como vadia, aproveitadora ou histérica.

O subtítulo do livro - Os bastidores do processo criativo de Breaking Bad, Família Soprano, Mad Men e outras séries revolucionárias - deixa claro que as séries masculinas, com protagonistas e equipes de produção formadas sobretudo por homens e temática masculina, são aquelas tidas como exemplares da tal revolução. E o que seria essa revolução? Segundo o autor, a partir de meados dos anos 80 ,

(...) em lugar de atrair um terço de toda a audiência (...), as redes agora almejavam demografias específicas: os ricos, os jovens, os instruídos, os homens e assim por diante. A fragmentação da audiência nos Estados Unidos havia começado. E, tal como tornaria a acontecer vinte anos mais tarde, isso era um bom sinal para a TV de qualidade (MARTIN, 2014, p. 63).

A expressão "TV de qualidade", usada por Martin (2014) no livro e também comum entre os pesquisadores da área, traz implícita a ideia de que a TV tende a não ser considerada entretenimento de qualidade. Assim, é preciso adicionar um qualificador, o "de qualidade", junto ao substantivo que designa o meio. Vale lembrar que um dos primeiros slogans da HBO era: "It's not TV. It's HBO", de forma a se distanciar simbolicamente de um meio considerado inferior. Mas o que fazia a TV ser considerada entretenimento para pessoas pouco exigentes?

Nas últimas décadas, diversos estudos vêm revelando que grande parte do preconceito em relação à TV advém de sua identificação a gêneros narrativos femininos, como o melodrama, presentes sobretudo nas telenovelas. Heloisa Buarque de Almeida (2002) reflete sobre este assunto a partir do que denominou "feminilização da telenovela". Segundo a autora, durante muito tempo a associação entre mulher e telenovela não foi questionada. "Mulheres teriam prazer especial em assistir às novelas porque elas falam de histórias de amor e de família, de conflitos amorosos e familiares, de final feliz, com beijos, casamento e, se possível, filhos" (ALMEIDA, 2002, p. 173). Ela explica que a associação entre telenovela e o universo feminino é um desdobramento de uma outra associação, que "aproxima o feminino do mundo familiar e doméstico" (2002, p. 174), associação que permanece a despeito da presença das mulheres no espaço público e no mercado de trabalho.

Segundo Esther Hamburger (2007, p. 155), a associação entre o gênero feminino e as telenovelas é parte de um fenômeno maior, que identifica a cultura de massas ao universo feminino. Para Patrice Petro (1986, p. 6), a discussão sobre a cultura de massas é quase sempre acompanhada de metáforas de gênero que associam valores femininos à cultura de massas e valores masculinos à verdadeira arte, opondo distração a atenção, passividade a atividade, e assim por diante (PETRO, 1986, p. 6). Essa associação é motivadora de uma série de pressupostos com relação ao gosto e ao repertório cultural das mulheres, uma vez que, seja na vertente de esquerda de Adorno e Horkheimer seja na de direita de Ortega y Gasset, a cultura de massas é considerada desprovida de originalidade, esteticamente conservadora, dirigida a um público pouco criterioso que rejeita o esforço intelectual. Na versão de esquerda da crítica, a cultura de massas é tida como tendo uma função ideológica de manutenção da ordem e alienação do trabalhador. 
Assim, a "revolução" de que fala Martin (2014) relaciona-se a uma transformação da serialidade na TV, de produtos eminentemente femininos para produtos masculinos, como os próprios citados The Sopranos (1999-2007), Breaking Bad (2008-2013) e Mad Men (2007-2015), que, ainda que muitas vezes lidem com temas tradicionalmente femininos, como a família, 0 fazem por um ângulo masculino ou, como dirá Teresa de Lauretis (1987), dirigindo-se ao espectador como homem. Nesse processo, as séries se distanciam simbolicamente das características usualmente atribuídas à cultura de massas - associadas ao universo feminino - e passam a ser analisadas com elementos de erudição, de modo que seus críticos começam a se debruçar minuciosamente não apenas sobre o roteiro, mas também sobre aspectos formais como edição, fotografia e direção de arte. O argumento que se desenrola no livro de Martin constrói uma associação entre o surgimento de uma TV de bom gosto e os produtos voltados ao público masculino, operando uma cisão entre a TV que se fazia até o começo dos anos 90 - de telenovelas rocambolescas e melodramáticas - para a TV que se faz hoje - com protagonistas supostamente bem construídos e eivados de ambiguidade moral. A mudança de status crítico e de recepção da telenovela latino-americana tradicional para as séries internacionais atuais nos remete à observação de Pierre Bourdieu (2017) sobre o que ocorre com as atividades domésticas femininas quando passam a ser realizadas por homens.

\begin{abstract}
(...) as mesmas tarefas podem ser nobres e difíceis quando são realizadas por homens, ou insignificantes e imperceptíveis, fáceis e fúteis quando são realizadas por mulheres, como nos faz lembrar a diferença entre um cozinheiro e uma cozinheira, entre o costureiro e a costureira: basta que os homens assumam tarefas reputadas femininas e as realizem fora da esfera privada para que elas se vejam enobrecidas e transfiguradas (BOURDIEU, 2017, p. 88).
\end{abstract}

É realmente incrível a eficácia desse processo, que transforma simbolicamente um gênero considerado divertimento obtuso em produto de qualidade. Não queremos negar que mudanças estéticas e de linguagem existam, mas o interessante é notar como se constrói a ideia de uma ruptura entre a serialidade até o final dos anos 80 e a contemporânea. Esse processo pode ser verificado, por exemplo, ao nos debruçarmos sobre gêneros e temáticas antes tidos como excessivamente masculinos e esteticamente inferiores e hoje reconstruídos com uma roupagem adequada ao espectador exigente, amplo, internacional, e que por isso tomam a aparência de falar a todos os públicos, independente de gênero ou raça.

É o caso de algumas narco-narrativas que fizeram sucesso recentemente, e que transfiguram a temática da violência e das drogas na América Latina em produtos adequados ao público contemporâneo internacional. Estamos pensando, sobretudo, nas três primeiras temporadas de Narcos (2015, 2016 e 2017), produção da Netflix que dramatiza eventos envolvendo o combate aos grandes cartéis de droga colombianos. Esse produto se difere de grande parte das narco-telenovelas produzidas tradicionalmente para as TVs latino-americanas, nas quais são apresentadas situações e ambientes sórdidos, interpretações consideradas exageradas, figurino e maquiagem extravagante, e narcocorridos ${ }^{1}$ na trilha sonora. Para exemplificarmos esta comparação, podemos citar outros produtos disponíveis na própria Netflix, como El Capo - El Amo Del Túnel (2016), série mexicana remotamente baseada em Joaquín Guzmán, Estocolmo (2016), série argentina sobre tráfico humano que explora violência e sexualidade, e La Reina Del Sur (201 1), telenovela mexicana produzida pela Telemundo baseada no livro do espanhol Arturo Pérez-Reverte, de mesmo nome, publicado em 2002.

Essas séries (mesmo La Reina Del Sur em sua primeira versão com Kate del Castillo) dirigem-se abertamente ao espectador masculino, explorando fórmulas voltadas ao homem cis, com cenas que mostram voyeuristicamente corpos femininos e a violência bruta entre homens pouco intelectualizados e muito impulsivos. Já Narcos, de maneira oposta, procura dissimular em certa medida o fato de que fala a um espectador masculino, envelopando as sequências de sexo e violência com motivações de roteiro, bem como edição e direção de arte cuidadosas comandadas por profissionais de cinema. Assim, a separação entre a TV tradicional e a "TV de qualidade" é formal e simbolicamente produzida: não mais um produto grosseiro, que almeja o homem latino-americano menos sofisticado, mas um entretenimento de nível "artístico", que apela a públicos contemporâneos diversos que normalmente não consumiriam narco-narrativas. Desse modo, ainda que a série não se dirija especificamente a públicos femininos, esta aparentemente não os ofende, e inclui elementos que permitam a identificação da espectadora com a narrativa apresentada. Escamoteia-se, em grande medida, a natureza profundamente masculina desse produto, embalando-a com uma estética agradável e suprimindo a violência lowbrow, francamente baixa, típica da cultura de massas abertamente dirigida a homens.

Em A Ideologia Alemã, Karl Marx e Friedrich Engels (2015) esboçaram uma teoria sobre a ideologia que irá impactar profundamente as ciências humanas e sociais e fornecer uma explicação eficiente para a identificação que muitos dos dominados sentem pelas ideias de

'Subgênero do "corrido", ritmo musical tipicamente produzido nas bordas entre México e EUA. 
seus dominantes. Ainda que, na sociologia da arte, a concepção de uma determinação da base econômica sobre a superestrutura não possa ser encampada sem mediações, a ideia de que uma dada ordem se mantém pelo fato de que as ideias dos dominantes aparecem como ideias universais é muito poderosa. Assim, adaptando o conceito a nosso assunto, é possível argumentar que um produto como Narcos atua de maneira muito mais complexa e perturbadora do que uma série abertamente hetero-masculina, justamente por permitir alguma identificação do público feminino com os eventos e personagens ali mostrados. Ao se apresentar como parte de uma estética universal, adequada ao entretenimento de bom gosto contemporâneo, Narcos disfarça em grande medida o fato de que tem no espectador masculino seu espectador ideal, naturalizando assim a sub-representação do gênero feminino sob uma estética elegante e roteiro bem construído enquanto faz dos personagens masculinos os grandes motores da ação e da narrativa.

Esse mecanismo de transformação ideológica do particular em universal torna difícil definirmos o que seria uma escrita ou uma estética feminina. Em Technologies of Gender, Lauretis (1987) aborda essa questão. Segundo a autora, a dificuldade advém de duas razões principais: em primeiro lugar, ela relaciona-se a um duplo desafio do movimento feminista, que deve ser propositivo e afirmativo politicamente, mas que, ao mesmo tempo precisa empreender uma crítica radical à sociedade patriarcal que engendra o discurso político corrente. Ou seja, um movimento a que deve se contrapor mas, ao mesmo tempo, participar do espaço político, pois não há outra forma de transformá-lo. A segunda razão relaciona-se à questão da linguagem, e liga-se à dificuldade de termos de atuar como sujeitos em uma estrutura de discurso que "nos nega ou nos objetifica através de suas representações" (LAURETIS, 1987, p. 127). Ou seja, a linguagem (que podemos entender no contexto da citada obra como também a linguagem do cinema, por exemplo), enquanto elemento estruturante das classificações e relações sociais, estabelece um lugar social e simbólico para a mulher que temos de confrontar, na falta de qualquer outro meio, a partir da própria da linguagem.

Lauretis cita Laura Mulvey em seu esforço de pensar o que seria um cinema feminista. Em um primeiro momento, pensou-se em transformar o conteúdo da representação cinematográfica (ou seja, aquilo que era dito pelo cinema), o que foi seguido de um segundo momento, no qual a preocupação era com a linguagem da representação (a forma como era dito, portanto). Mulvey defende a destruição do cinema narrativo e do prazer visual como uma forma de des-objetificar a imagem da mulher, apostando no contracinema feminista como alternativa (LAURETIS, 1987, p. 128). Para Lauretis, no entanto, isso não responde exatamente à questão do que seria uma escrita feminina, além de apontar para um problema complementar: haveria realmente uma única linguagem estética feminina, ou isso seria escamotear diferenças entre as mulheres - mulheres racializadas, lésbicas, mulheres que usam véu, mulheres da classe trabaIhadora etc.? Diante das dificuldades em se pensar uma escrita feminina é que Lauretis defende a ideia de pensarmos um cinema que "dirija-se ao espectador enquanto mulher, mais do que retrate a mulher positiva ou negativamente" (LAURETIS, 1987, p. 135).

Ao recusar o espetáculo narrativo do cinema e do audiovisual, que as séries contemporâneas exploram muito bem ao articular o prazer folhetinesco do texto a belas imagens, a proposição de Mulvey citada por Lauretis parece rejeitar toda forma de entretenimento. O ensaio Visual Pleasure and Narrative Cinema foi escrito em 1975, período no qual a Teoria Crítica de Adorno e Horkheimer e sua denúncia da indústria cultural gozava de bastante prestígio nos estudos da cultura de massas. Era um contexto teoricamente propício a argumentos que analisassem 0 cinema como fator de manutenção da ordem, seja capitalista seja patriarcal. Além disso, as ferramentas teóricas usadas por Mulvey baseiam-se na psicanálise freudiana e lacaniana, que sabemos ser muito falocentradas. Pensando o panorama atual, sobretudo no momento em que as séries se tornam um produto altamente consumido e valorizado - inclusive pela crítica -, a proposição de Mulvey coloca um problema àqueles que, como nós, estamos interessados nas construções simbólicas que estão efetivamente sendo consumidas pelo público e que, portanto, têm forte potencial de disseminação de representações. Seria necessário refletirmos sobre uma forma de resistência ao patriarcado que, no interior da cultura de massas, seja consumida por grande número de espectadoras e ao mesmo tempo ofereça possibilidades alternativas de identificação e subjetivação.

O conceito de série praticamente se choca com a proposta de um audiovisual de vanguarda. A serialidade moderna, que inclui a telenovela, tem sua origem no folhetim, cujo objetivo principal era contar uma boa história de modo que os leitores comprassem jornais todos os dias. O gênero precisava explorar o prazer e o desejo do leitor de acompanhar a história e seus personagens em suas peripécias rocambolescas - expressão originada do mais famoso personagem de folhetim, Rocambole. Da mesma forma, na contemporaneidade, muitos países latino-americanos param para acompanhar os capítulos finais de uma telenovela e fãs do mundo inteiro anseiam avidamente pela estreia da nova temporada de um $T V$ show. 
Vincent Colonna (2015), em L'Art de Séries Télé (2015), defende que as séries se caracterizam, antes de tudo, pela narrativa, pelo enredo, por uma história bem contada. Segundo ele, é isso que faz o sucesso das séries estadunidenses, e é isso que os produtores europeus demoraram tanto tempo para perceber, presos que estavam a uma tradição cinematográfica europeia de vanguarda que tinha na forma sua qualidade principal:

A noção de originalidade não tem sentido na televisão, à diferença do cinema; e os personagens não podem ser o fundamento de uma série, pois eles não resistiriam ao desgaste da repetição dos episódios (...). Quando o produtor hollywoodiano David O. Selzick dizia que um bom filme é baseado em três coisas: uma boa história, uma boa história e de novo uma boa história, não era uma boa definição do cinema, mas sobretudo da série de TV (COLONNA, 2015, p. 23, tradução nossa). ${ }^{2}$

Assim, nosso desafio, nosso problema de investigação, consiste em analisar de que modo produtos massivamente consumidos e produzidos segundo uma estética aparentemente "neutra", internacional, profissional, contrastada à telenovela, dirigida a um amplo espectro de consumidores "exigentes", sub-representa a contribuição feminina na sociedade latino-americana e constrói uma visão de mundo dirigida sobretudo ao público masculino. A questão que se coloca é de que modo séries de temática tradicionalmente masculina - o narcotráfico - aparecem como destinadas a um público mais amplo, menos machista, mas acabam reforçando os estereótipos sociais tradicionais, de forma talvez ainda mais misógina do que uma telenovela (que, como vimos, tende a ser vista como um produto inferior à TV tradicional).

Para isso, escolhemos abordar aqui a representação feminina de uma das temporadas da mencionada série Narcos (2017), que tem em sua equipe profissionais de reputação internacional e passagem no cinema, como o diretor José Padilha (um dos produtores executivos da temporada) e o ator Javier Cámara. Trataremos da terceira temporada, que não tem Pablo Escobar como personagem, mas os narcotraficantes do Cartel de Cali. Sem Pablo Escobar a série perde um personagem masculino importante, extremamente hetero-orientado, um "autêntico" macho latino-americano que ama sua família enquanto se relaciona com amantes e prostitutas. Trata-se, talvez, da temporada de Narcos, incluindo Narcos México, que apresenta uma masculinidade latino-americana menos estereotipada, pois os narcotraficantes em questão se apresentam inicialmente como homens menos violentos e mais refinados, e portanto talvez seja a temporada que se apresenta como mais "universal", com modelos masculinos mais matizados. A série constrói sobretudo uma representação da mulher latino-americana, mas também de mulheres gringas inseridas em um contexto latino-americano. Trata-se de um grupo bastante específico, tendo em vista que, sobre a mulher latino-americana, a influência das instituições e dos valores patriarcais continua muito perceptível, seja no ambiente profissional, doméstico, na participação política, nas leis reprodutivas, na assistência junto ao poder público, mas também na representação no interior da cultura de massas, como o exemplo de Narcos nos chama atenção.

É possível argumentar que o lugar ocupado pela mulher nesses produtos audiovisuais corresponde ao lugar ocupado pela mulher no universo "real" dos narcotraficantes. Ou seja, haveria uma correspondência entre a ficção e o "real" no qual ela se inspira. Ainda que Narcos seja inspirado em fatos reais, admitimos estas séries como construções ficcionais imagéticos-sociais dirigidas a públicos amplos e que elaboram uma determinada visão de mundo sobre mulheres latino-americanas que se ligam a narcotraficantes, e não como formas de acesso não mediado à realidade das mesmas. Nossa concepção de representação, nesse sentido, se aproxima daquela de representação social conforme analisada por Denise Jodelet (2017) a partir dos estudos de Serge Moscovici, ou seja, como uma modalidade de conhecimento sobre o mundo que tem eficácia prática, que compõe a experiência cotidiana dos indivíduos e grupos sociais e que se caracteriza como um misto entre "real" e "ideal", residindo entre a concretude dos fenômenos sociais e sua ideação (JODELET, 2017, p. 26-43). A imagem criada a partir da representação social não se confundiria aqui nem com o ilusório (ou ideologia), nem com uma forma de acesso ao inconsciente do artista, nem com atitudes estéticas-criativas analisáveis em si mesmas, mas como uma forma de conhecimento sobre o mundo que, ao mesmo tempo em que é criado pela coletividade, exerce impacto nela. Dessa forma, enquanto produtos de ficção massificados e populares, estas séries ajudam a construir uma representação das mulheres que passa a potencialmente ter efeito "real", prático, legitimando simbolicamente determinadas atitudes em relação à mulher e ao corpo feminino que já se encontram difundidas na sociedade. Deve-se considerar, efetivamente, que entre o "real" e sua representação não há exatamente uma separação, pois não é concebível a vida material sem a sua simbolização: "Toda representação pressupõe a existência do real, mas este real só vem à consciência na

2 "La notion d'originalité n'a pas de sens em télévision, à la différence du cinema; et les personnages ne peuvent être au fondement d'une série, car ils ne résisteraient pas à l'usure qu'entraîne la répétition des épisodes [...]. Quand le producteur hollywoodien David O. Selznick disait qu'un bom film reposait sur trois choses: une bonne histoire, une bonne histoire et encore une bonne histoire, ce n'etait pas une bonne definition du cinema, mais plutôt de série télé." 
medida em que uma representação o afirma e o torna passível de descrição" (Hans BELTING, 2007 , p. 38 , tradução nossa). ${ }^{3}$

A representação feminina no universo do narcotráfico é um tema atual e relevante, na medida em que a narco-cultura se torna popular não apenas em seu ambiente de origem, mas também na cultura de massas mundializada. Em outras palavras, a narco-cultura, para usar os termos de Renato Ortiz (1994), se tornou internacional-popular, desenraizando-se de seu local de origem. Assim, é preciso levar em conta não apenas os aspectos sociais da representação, que segundo Jodelet (1991, p. 41) articulam-se aos elementos afetivos e mentais que integram a cognição, mas também a forma específica por meio da qual essas representações são comunicadas: "a comunicação social, sob os aspectos interindividuais, institucionais e midiáticos aparece como condição de possibilidade e de determinação das representações e do pensamento social" (JODELET, 1991, p. 47, tradução nossa) ${ }^{4}$ A cultura de massas internacional-popular tornou-se uma importante forma de sistematizar e comunicar as representações. No entanto, além de seu desenraizamento local e de seu profundo entrelaçamento na sociedade mundializada, as séries usufruem das prerrogativas da imagem em movimento, ontologicamente ligada ao "real", conforme teorizado de maneira fundamental por André Bazin (2002) e Belting (2007) e discutido por Paulo Menezes (2000) e Marina S. Jorge (2013): a representação na imagem de tipo cinematográfica, pela natureza de seu processo mecânico de produção (Bazin) e pela identidade entre imagem e veracidade produzida no interior do cristianismo (Belting), carrega consigo a aparência de falar sobre o real de maneira direta e pouco mediada. Em suma, Narcos expressa e comunica imageticamente representações sociais sobre homens e mulheres ligadas ao narcotráfico ao mesmo tempo em que produz essas representações na coletividade, e o faz a partir de um meio visual que carrega tanto ontológica quanto culturalmente uma forte impressão de realidade (e, portanto, de convencimento).

Narcos conta com pouquíssimas mulheres em sua equipe de produção. Tradicionalmente, os gêneros de ação são considerados territórios masculinos, e só mais recentemente temos visto mais diretoras e roteiristas trabalhando nesse campo. Não há nenhuma diretora creditada em Narcos, nem nessa temporada nem nas anteriores. Há apenas duas roteiristas creditadas nessa temporada, Ashley Lyle, no episódio 5, chamado MRO, e Santa Sierra, no episódio 7, Sin Salida. Assim, mesmo nos bastidores, a série revela-se como um espaço masculino. Nesse sentido, ainda que não seja uma série de temática considerada feminina, pelo fato de representar mulheres, é possível dizer que se trata da representação dos subalternizados segundo a voz dos dominantes. Citando o importante texto de Gayatri C. Spivak, Pode o subalterno falar?, Eduardo Rabenhorst e Raquel Carmargo (2013) explicitam: "os grupos marginalizados são sempre intermediados pela voz de outrem, isto é, por aqueles que possuem o poder de representar e de descrever, e que controlam, assim, a maneira como os que não detêm idênticos poderes serão vistos" (RABENHORST; CARMARGO, 2013, p. 992).

A antropologia estrutural nos mostra que é preciso entender a sociedade de forma relacional, de modo que não basta compreender a imagem da mulher na obra escolhida, mas inseri-la no sistema inter-relacional de representações dos gêneros. Assim, trataremos brevemente também de personagens masculinos e de masculinidades, uma vez que a representação dos homens e a das mulheres constrói-se mutuamente: "Masculinidade e feminilidade são conceitos inerentemente relacionais, que têm significado um em relação ao outro, como demarcação social e oposição cultural" (Robert CONNELL, 2005, p. 43, tradução nossa). ${ }^{5}$ Nossa perspectiva de masculinidade aproxima-se, portanto, daquela explicitada e analisada por R. W. Connell: "configurações de práticas estruturadas por relações de gênero" que são "inerentemente históricas e que constroem e reconstroem o processo político afetando o equilíbrio dos interesses na sociedade e a direção da mudança social" (CONNELL, 2005, p. 44, tradução nossa). ${ }^{6}$

Muitos atores, como Benedito Medrado e Jorge Lyra (2008), Miriam Grossi (2004) e Nelson Martini (2002), consideram e demonstram, inclusive a partir de estudos empíricos, que não há apenas uma masculinidade, mas várias, que "às vezes se sucedem umas as outras, e as vezes coexistem" (MARTINI, 2002, p. 22). Grossi cita estudos no Brasil que apontam "múltiplos modelos de masculinidade", tais como "homens honrados, homens sensíveis, novos pais, homens desempregados etc." (GROSSI, 2004, p. 28). Para o assunto desta pesquisa, interessa, sobretudo, refletir, a partir de Grossi, sobre a agressividade como característica tradicionalmente associada à masculinidade, o que explica em parte o fato de os homens, sobretudo em contextos de exclu-

\footnotetext{
3 "Toute représentation présuppose l'existence du réel, mais ce réel n'advient à la conscience que dans la mesure où une représentation l'affirme et le rend descriptible."

4 "Ainsi la communication sociale, sous ses aspects interindividuels, institutionnels et médiatiques apparaît-elle comme condition de possibilite et de détermination des représentations et de la pensée sociales."

5 "Masculinity and femininity are inherently relational concepts, which have meaning in relation to each other, as a social demarcation and a cultural opposition."

6 "Masculinities are configurations of practice structured by gender relations. They are inherently historical; and their making and remaking is a political process affecting the balance of interests in society and the direction of social change."
} 
são social, associarem-se mais frequentemente a criminalidade e violência. As narco-narrativas reforçam a associação entre homens e violência, ao representarem personagens masculinos como naturalmente inclinados ao narcotráfico e bastante confortáveis em um ambiente de criminalidade.

Ainda que não se possa reduzir masculinidades a "formas binárias que supõem a divisão entre formas hegemônicas e subordinadas", conforme alertam Medrado e Lyra (2008, p. 824), o modelo proposto por Michael S. Kimmel (1998) nos ajuda a pensar a emergência de um ideal de masculinidade na primeira metade do século XIX que, enquanto se constituía como hegemônico, desvalorizava outras identidades masculinas. Assim, ideais hegemônicos e subalternos de masculinidade desenvolveram-se mútua e simultaneamente:

Na primeira parte do século XIX (...) uma nova versão de masculinidade emergiu, a do Self-Made Man. A sua masculinidade deveria ser demonstrada e provada no mercado. Ele era um empresário urbano, um homem de negócios, um homme d'affaires. (...) Tal definição de masculinidade era inerentemente instável, exigindo comprovação constante, incluía sempre o risco de falhar. A masculinidade deve ser provada, e assim que ela é provada, ela é novamente questionada e deve ser provada ainda mais uma vez; a busca por uma prova constante, durável, inatingivel, torna-se em última instância uma busca tão sem sentido, que ela assume as características, como disse Weber, de um esporte (KIMMEL, 1998, p. 111).

Os personagens masculinos ligados ao narcotráfico da nossa temporada encampam, em grande medida, esse ideal do self-made man, ainda que aplicado aos negócios ilícitos, pois são construídos como homens bem-sucedidos que nunca estão satisfeitos com o que alcançaram até o momento. Em realidade, esse é o mote de todo o conflito da temporada, uma vez que esta começa com os narcos rebelando-se contra a decisão de seu chefe, Gilberto Rodríguez, de encerrar as atividades do cartel e partir para negócios lícitos menos arriscados e possivelmente menos lucrativos.

Assim, agressividade e sucesso no mercado combinam-se em Narcos na construção de personagens masculinos identificados sobretudo à masculinidade hegemônica, ainda que esta apareça mesclada a outros tipos de masculinidade, como o bom pai, o bom marido e policial honrado. É na relação com esta masculinidade hegemônica que as personagens femininas de Narcos são construídas.

Em relação às primeiras duas temporadas de Narcos, falta na terceira temporada a presença forte de uma família, como era a de Pablo. A família, como espaço identificado à mulher, costuma ser preenchida por personagens femininos, como Tata (Paulina Gaitan) e Hermilda (Paulina García) nas primeiras duas temporadas, esposa e mãe de Escobar. Na terceira temporada há algumas famílias, mas elas não têm a importância da família de Escobar ou não estão unidas, em sua maioria, por fortes vínculos afetivos, como a dele. O vínculo de parte das famílias mostradas na terceira temporada é, na verdade, mais material do que emocional.

As três esposas do grande chefe do Cartel de Cali, Gilberto Rodríguez, aparecem brevemente em apenas um episódio e não têm nomes (por isso não podemos creditar as atrizes). Elas estão na série para ajudar a caracterizar Gilberto como alguém meticuloso, hábil, que é capaz de coordenar pessoas e organizar a rotina, tanto em casa quanto nos negócios, para que todos colaborem e atuem com o mesmo objetivo. Sem autonomia própria, essas esposas estão inseridas na série para ajudar na caracterização do personagem masculino. Ter três esposas é apresentado como uma virtude de Gilberto, e subentende-se da série que se trata de uma fantasia de posse que todo homem deve ter, ainda que só os bem-sucedidos possam alcançar. As esposas dividem a atenção do marido em dias específicos da semana, e no domingo todas se juntam a ele para acompanhar o futebol. É um pacto que parece funcionar tanto para Gilberto quanto para as esposas, que aceitam alegremente o acordo, segundo a série sugere, pois assim mantêm a vida de luxo. Trata-se, portanto, de mulheres "mantidas", que são vistas fazendo a unha umas das outras, indo às compras, tomando espumante e fazendo sexo com Gilberto. O sexo, nesse caso, é performatizado de modo a dar prazer a Gilberto e não necessariamente à sua esposa, uma vez que se trata de uma cena de felação. Em nenhum momento é mencionada uma atividade profissional envolvendo algumas delas, pelo contrário, há uma ênfase ostensiva no lazer. Não sabemos sequer qual delas é a mãe do filho advogado de Gilberto, que aparece em diversos momentos da temporada como uma pessoa estudada e razoável, que dá bons conselhos ao pai. Assim, as esposas de Gilberto são mostradas, ainda que brevemente, como mais imaturas e infantilizadas do que seu jovem filho.

Um segundo núcleo familiar composto por uma mulher mantida é o de Miguel, irmão de Gilberto, segundo na hierarquia do Cartel, mas menos inteligente, inábil articulador e mais impulsivo. Maria Salazar (Andrea Londo), a companheira de Miguel, inicia a terceira temporada como esposa de Cláudio, um narcotraficante membro da família Salazar, do Cartel do Norte del Valle. Maria é bonita segundo os padrões de beleza convencionais do patriarcado, veste-se 
com roupas justas, e tem um rosto redondo angelical e fotogênico, o que confere à personagem um misto de sensualidade e inocência (em sua primeira aparição ela está usando um vestido justo e curto, mas branco e de tecido fino). A série a representa como uma mulher-troféu, que faz parte dos itens de consumo de luxo de um narcotraficante, ainda que seu figurino, cabelo e maquiagem procurem equilibrar vulgaridade e elegância. Seu primeiro marido é brutalmente assassinado em um acerto de contas, logo no primeiro episódio, por Pacho Herrera, sócio dos irmãos Rodríguez e um dos personagens principais da terceira temporada. Após passar todo o segundo episódio procurando o marido, ela descobre que ele está morto. No terceiro episódio, Maria percebe que precisa de um novo homem para protegê-la, o que significa pagar suas despesas e a de seu filho e manter seu padrão de vida. Morar com sua sogra não parece possível, uma vez que esta é representada como uma mulher irascível e machista. Maria aceita a proteção de Miguel Rodríguez, com quem havia flertado discretamente no primeiro episódio da temporada, e torna-se sua companheira. Assim como Miguel não tem habilidade para o trato político, ele também não é capaz de conquistar uma mulher pela sedução. A relação entre ele e Maria se inicia de maneira ostensivamente fria, constrangedora, como se ele tivesse comprado uma esposa, mas depois não soubesse muito bem o que fazer com ela.

O acordo entre os dois, no entanto, fica bastante claro e é representado como conveniente para ambos, ainda que não exista paixão entre eles. Há respeito e certo carinho mútuo no desenvolvimento da relação, mas Miguel, quando se percebe em perigo, passa a gritar e a se aborrecer com ela. Segundo sugerido pela série, Miguel quer uma mulher-troféu, enquanto Maria quer manter seu padrão de vida e dar conforto e proteção a seu filho. Miguel parece relacionar-se com um corpo e Maria com o luxo e a tranquilidade que o acordo lhe oferece, pois a série enfatiza determinados aspectos frívolos de seu cotidiano - em determinada sequência, após o sexo, Miguel levanta-se para resolver algo importante enquanto Maria abre um estojo de maquiagem e se olha no espelho. Dessa forma, o que está sugerido em Narcos é que Maria é, assim como outras, uma mulher que se liga ao narcotráfico para desfrutar de um elevado padrão de vida. O fato de que ela não tem realmente escolha, no contexto da trama, a não ser sujeitar seu corpo a homens poderosos e violentos como Miguel, na medida em que tem um filho pequeno e que precisa sobreviver, é muito pouco enfatizado. A partir de Maria, a série poderia tematizar o enorme impacto do narcotráfico, da violência, da ameaça da pobreza e da repressão policial na vida das mulheres, uma vez que o cuidado com o outro, tarefa culturalmente feminina, torna-se ainda mais penoso nesse contexto. Ainda que Narcos nos dê elementos para compreender a escolha de Maria como necessidade de sobrevivência, essa leitura é em certa medida obstacularizada por outras características atribuídas à personagem, inclusive sua rápida adaptação ao novo marido, o que inclui sequências de sexo construídas para parecerem prazerosas para ambos.

A relação entre Maria e Miguel reproduz alguns dos lugares comuns da representação das sexualidades masculina e feminina: o desejo sexual é aqui um atributo masculino. Maria é sexy, veste-se e mantém-se linda, mas ela é claramente um objeto que visa estimular o olhar do homem, que é a parte do casal que efetivamente deseja. Conforme a breve cena em que se olha no espelho, depois do sexo, deixa claro que - pois neste momento não há ninguém para vê-la além de ela mesma - sua objetificação é algo introjetado, e nesse sentido um atributo "natural" feminino que a série reproduz sem questionar. De tanto saber-se um objeto do olhar, Maria toma para si a tarefa de cuidar de sua própria objetificação, à maneira descrita por John Berger (2008) em Modos de Ver: na medida em que se sabe continuamente vista pelo olhar alheio, a mulher está sempre acompanhada de sua própria imagem, que ela mesma passa então a controlar. Teremos de voltar à Maria ao final desse texto, pois ela protagoniza uma bela cena de vingança pessoal e sobrevivência material. Por hora, continuaremos com as famílias.

Uma terceira família desprovida de laços afetivos fortes é a do contador do Cartel de Cali Guillermo Pallomari e sua esposa Patricia (Lina Castrillón). Aqui, novamente, há uma incompatibilidade no casal: Guillermo é louco por Patricia, mas ela visivelmente o despreza. Ao final da temporada saberemos que ela tem um amante, que é o que leva os agentes estadunidenses da Drug Enforcement Administration (DEA) a encontrar Pallomari antes dos traficantes. À diferença das famílias anteriores, Patricia não é uma mulher mantida, mas trabalha e tem sua própria empresa. Isso the permite fazer planos de vida que não incluem o marido, e ela pensa mesmo em abandoná-lo. Apesar de ser apresentada como uma bem-sucedida empresária, em duas ocasiões, em meio ao perigo, sua superficialidade se sobressai à inteligência: quando Jorge Salcedo transfere a família de casa para sua proteção (apesar de ser um bom apartamento, sem luxo, mas adequado, Patricia reclama) e quando a DEA oferece ao casal a oportunidade de entrar para o programa de proteção à testemunha nos Estados Unidos. Nesse sentido, Patricia complementa a caracterização de Guillermo Pallomari como pessoa esnobe e egoísta na medida em que este também demora a desapegar-se de sua vida de luxo na Colômbia, mesmo em situação de risco de vida para a família. Portanto, ainda que ambos tenham empregos de responsabilidade - ele como contador do cartel é responsável por todas as propinas -, eles não 
são apresentados como pessoas muito perspicazes. Colabora nessa caracterização o amante de Patricia, apresentado em grande medida como um idiota que é ingênuo o suficiente para se arriscar a negociar com o cartel e acaba com os ossos da mão esmagados. Nesse sentido, não surpreende o espectador que Patricia tenha um amante, pois o desprezo dela pelo marido é bastante evidente, mas surpreende que ela tenha se apaixonado por alguém tão obtuso, talvez mais desinteressante ainda do que o marido. O personagem do amante, portanto, colabora na caracterização de Patricia.

Uma quarta família, talvez a que tenha maior importância narrativa e cujos laços afetivos são reais, é de Jorge Salcedo e sua esposa Paola (Taliana Vargas). Jorge Salcedo é um dos protagonistas da terceira temporada e o responsável pelo desmantelamento do Cartel de Cali. Encarregado da equipe de segurança de Miguel Rodríguez, ele percebe-se em uma situação complicada: não se identifica com o mundo do crime e quer montar uma empresa, mas não consegue se desvencilhar dos pedidos de Miguel - que não são exatamente pedidos, mas imposições mal disfarçadas - para que continue seu trabalho. Ao mesmo tempo, com os agentes da DEA perseguindo o cartel, Miguel e seu filho David tornam-se cada vez mais paranoicos e violentos. Salcedo sabe que precisa deixar o cartel, e percebe que a única saída é colaborar com a prisão de Miguel.

A esposa de Jorge Salcedo, Paola, é descrita como uma advogada competente, a "estrela" de seu escritório, e tem planos já bastante adiantados de abrir uma empresa de segurança junto com seu marido. Ainda que talvez seja a personagem feminina mais nuançada da série, com cuja vida grande parte das espectadoras pode se identificar, sua primeira aparição é em segundo plano e completamente desfocada por vários segundos, enquanto o marido é focalizado no primeiro plano. Em um nível formal, o enquadramento antecipa o que acontecerá ao longo dos episódios: o projeto profissional de Paola ficará em segundo plano em relação à trajetória do marido e ela tem de atuar a reboque das decisões dele. A abertura da empresa de segurança será impossibilitada pelo fato de Salcedo não conseguir desvincular-se do Cartel de Cali, o que resulta em tensões constantes entre o casal. Paola veste-se de modo adequado a seu status pessoal e profissional, com tailleurs femininos no trabalho e vestidos compridos e floridos no lazer, e em nenhum momento é caracterizada como frívola ou pouco inteligente. Ela é mostrada indo ao trabalho, mas também desempenhando funções de mãe, o que pouco ocorre com as outras mulheres da série. Os dois aspectos da reprodução social capitalista (produção de bens e serviços e produção da vida) são vistos aqui como perfeitamente conciliáveis. Em realidade, Paola e Jorge são os únicos pais vistos em rotinas de cuidado com os filhos. Sabemos que Maria tem um filho mas, ao contrário, ela não é vista colocando-o para dormir, levando-o na escola ou contando histórias para ele. Isso também não ocorre com Guillermo e Patricia. Isso nos leva a concluir que, na série, as mães mais ligadas ao narcotráfico são representadas como piores mães, talvez porque mais preocupadas com questões consideradas fúteis, como itens de consumo de luxo e ostentação. A maternidade, portanto, é tratada aqui como extensiva à moralidade, de modo que as "melhores" mulheres aparecem também como "melhores" mães. Seja como boa profissional, seja como boa mãe, as características de Paola complementam a construção do personagem de Jorge Salcedo (assim como ocorre entre Patricia e Guillermo): ele um homem simples, competente profissionalmente, que não é afeito à ostentação, e que não se identifica com o narcotráfico.

Assim como as primeiras duas temporadas de Narcos, a terceira temporada também coloca em cena a figura da gringa desinserida na sociedade colombiana. Antes era Connie Murph (Joanna Christie), esposa do agente da DEA Steve Murph, que não conseguia se adaptar a Bogotá. Agora temos Christina Jurado (Kerry Bishé), estadunidense, esposa de Franklin Jurado, que movimenta as contas bancárias ligadas ao Cartel de Cali. Christina, como Connie, é incapaz de aprender a falar espanhol e de encontrar um trabalho (ainda que tenha um diploma de Harvard, mencionado na série). Por ser cidadã dos EUA, tem facilidade para abrir contas em paraísos fiscais, algo útil para o trabalho do marido. Veste e se penteia de maneira elegante e discreta, sem a ostentação vulgar que caracteriza algumas mulheres colombianas ligadas ao narcotráfico na série. Entediada e sozinha na Colômbia, ela faz uso de drogas.

A solidão de Christina faz com que ela seja vista como alvo fácil de sedução pelo agente da DEA Javier Peña, o que não chega se concretizar. Ainda que ela seja convencida a colaborar com a DEA, não o faz pelo charme do agente, e sim para proteger seu marido. $O$ fato de Peña não ter conseguido levá-la para a cama é um alívio, tendo em vista a capacidade do agente de seduzir mulheres. Isso nos leva a um outro grupo de personagens femininas, bastante pequeno, mas relevante em termos de construção da imagem da mulher, que são aquelas que estão na série para serem seduzidas por Peña.

Javier Peña é interpretado por Pedro Pascal, chileno, um homem bonito e que na série é caracterizado como irremediável sedutor e incapacitado para relações afetivas. A primeira sequência da segunda temporada nos mostra uma festa de casamento no Texas, onde Javier está com seu pai. Ele se dirige a uma mulher e pede desculpas a algo que fez a ela dez anos 
atrás, ao que ela responde que já o perdoou faz tempo e que é até grata pelo que aconteceu, já que o casamento entre os dois não teria sido feliz. É interessante notar que esta primeira sequência, passada nos EUA, não colabora de maneira nenhuma para fazer avançar a narrativa sobre o Cartel de Cali, que é o assunto da temporada, e parece ter sido colocada ali apenas para mostrar a incapacidade de Peña para o amor. No entanto, ao longo da série, e não apenas nessa temporada, ele seduz um grande número de mulheres, seja colegas de trabalho, informantes ou simplesmente mulheres para quem ele olha no bar. Não apenas ele é bonito e sedutor, mas em alguns momentos ele não precisa fazer nada além de se sentar ao balcão de um bar e esperar que alguma mulher no ambiente lance um olhar para ele. O personagem de Peña é bastante revelador de certa imagem das mulheres na série: tudo se passa como se elas não conseguissem resistir a determinados homens, sobretudo àqueles que irão magoá-las. De alguma forma, é como se as mulheres fossem responsabilizadas por procurarem homens incapazes de estabelecer uma relação afetiva.

Ainda que Peña seja caracterizado como este homem irresistível e conquistador (não apenas nessa temporada que estamos analisando), há uma mulher, um pouco mais velha que as outras personagens, cujo papel é pequeno, mas interessante, que não estabelece nenhum vínculo passional com homem algum, e que está na série estritamente por sua atividade profissional: trata-se de Carolina Alvarez (Margarita Rosa de Francisco), jornalista investigativa que apura crimes ligados ao Cartel de Cali. Logo no início da temporada, ela procura Peña para que este seja seu informante dentro da DEA, e a espectadora acostumada com Narcos possivelmente infere que favores sexuais estejam incluídos na proposta. Felizmente, a relação entre Peña e Carolina é apenas profissional. Ambos trabalham juntos para demonstrar que o Cartel de Cali tem relações com a Presidência da República. No entanto, Peña é o protagonista, e o vemos em ação para chegar a essas conclusões, enquanto o trabalho investigativo de Carolina não nos é mostrado.

Ao contrário do Cartel de Medellín, liderado por Pablo Escobar, o Cartel de Cali é descrito na terceira temporada como lugar de homens elegantes, discretos e refinados. Em relação ao grupo de Escobar, são homens que, como já mencionamos, expressam uma masculinidade menos bruta, mais sofisticada e um pouco mais diversa, ainda que no âmbito da masculinidade hegemônica. Além dos irmãos Gilberto e Miguel, do cartel fazem parte Chepe Santacruz e Pacho Herrera. Este último é um homem abertamente gay, e sua homossexualidade não é um problema para seus sócios e para seu trabalho de modo geral. A série mostra-o como um homem bem vestido e extremamente violento. Ele é responsável pelo assassinato do primeiro marido de Maria e o faz da maneira brutal, ao amarrar cada um de seus membros a uma moto e despedaçá-lo. Ao final da temporada ele promove mais um massacre, assassinando todos os membros da família Salazar. A associação entre homossexualidade e violência precisaria de mais tempo para ser analisada, mas é possível considerar que fica implícita, na série, uma associação entre dois "desvios à normalidade": o personagem que recusa a heteronormatividade é também o que se destaca em termos de psicopatia. Um dos parceiros sexuais de Pacho é um rapaz negro sem nome, funcionário do Cartel, e com quem estabelece uma relação de evidente desigualdade.

Nesse mesmo sentido, outro tema que poderia ser mais bem desenvolvido em pesquisas futuras é a subalternidade de personagens masculinos negros e ameríndios em Narcos de modo geral. Na terceira temporada temos pouquíssimos homens (e também mulheres) racializados representados, sobretudo se considerarmos que estamos tratando de uma série latino-americana e que se passa na Colômbia, país com passado colonial e escravocrata. Assim, juntando as duas questões, o sadismo na representação do personagem gay e a sub-representação de negros e ameríndios, veremos que temos uma temporada não apenas orientada pelos personagens masculinos, mas por personagens masculinos brancos heterossexuais, que são representados, seja como heróis ou vilões, como modelos mais próximos do ideal de masculinidade.

Por outro lado, a temporada inverte algumas expectativas relacionadas a mulheres e violência, sobretudo se pensarmos que nas duas primeiras temporadas as mulheres eram mais coniventes com a violência, mas menos ativas. Isso nos chama atenção para o fato de que os produtos culturais, mesmo os mais unidimensionais, não eliminam toda possibilidade de contraleitura e todo vislumbre de imagem de resistência dos sub-representados. O massacre final, orquestrado por Pacho, só funciona porque duas jovens usam de sua aparente inocência para assassinar friamente os seguranças que protegem a entrada da propriedade da família Salazar. Mais interessante, e nesse ponto voltamos à Maria e fechamos nossa análise, é sua atuação decisiva ao final da temporada, empreendendo uma ação que é ao mesmo tempo uma vingança pessoal, uma jogada estratégica e uma ação fundamental para o desmantelamento do Cartel de Cali.

No último episódio da terceira temporada Miguel está preso e Maria se vê sem um homem para protegê-la, o que a leva a procurar a ajuda do filho de Miguel, David Rodríguez. David é caracterizado durante toda a temporada como o principal vilão da história, pois é agressivo, frio, ambicioso, violento, e é quem impõe os principais obstáculos para o desfecho 
feliz da temporada. Mantendo seu padrão vil como personagem, David a humilha e diz que não se importa com Maria, ainda que seu pai se importasse com ela (Miguel havia dado instruções explícitas para garantir seu bem-estar), e recomenda: "abrid las piernas a alguien más, que es muy buena para eso".

A mise-en-scène é cuidadosamente construída, com Maria unicamente em foco, expressão de profunda raiva, e quatro homens emoldurando-a, de modo a estabelecer uma situação de poder inequívoca. A presença dos outros homens que testemunham a cena enfatiza a humiIhação sofrida por Maria, e podemos antever, senão notar efetivamente, os sorrisos que revelam a satisfação de ver uma mulher rebaixada. Ao mesmo tempo, o enquadramento exacerba a enorme assimetria: ela é uma só, tendo de negociar com um poderoso traficante cercado por vários sicários. É possível notar a dinâmica escópica do fotograma, que evidencia Maria como objeto do olhar dos homens presentes, um espetáculo para o gozo sádico masculino, e o próprio olhar da personagem, que nesse momento está desprovida de qualquer poder. A mulher-troféu, que todo narcotraficante deseja incluir no rol de seus objetos de luxo, rapidamente se torna objeto de desprezo, e agora é a "puta" ou a "perra" que não lhes serve mais.

A vingança de Maria não tardará, pois ela saberá dar utilidade bastante prática à sua condição. Minutos depois, no mesmo episódio, ela aparece na casa de Orlando Salazar, do Cartel do Norte del Valle, irmão de seu primeiro marido, pedindo proteção. Orlando pergunta-lhe o que ela tem para oferecer em troca da proteção, e a sequência encerra-se sem a resposta, deixando o espectador com a sensação de que Maria pode ter oferecido favores sexuais-afetivos novamente. Dez minutos depois, nesse mesmo episódio, tempo suficiente para que outras sequências façam o espectador se esquecer do assunto de Maria, David Rodríguez sai de seu esconderijo com seus sicários e é assassinado por membros do Cartel do Norte del Valle. O que Maria havia oferecido era a localização do filho de Miguel Rodríguez, garantindo ao mesmo tempo uma vingança pessoal e um lugar de proteção no novo contexto do narcotráfico. O fato da delação de Maria ter ocorrido fora de cena é importante para criar a surpresa na morte de David, e caberá ao espectador recriar os acontecimentos imediatamente anteriores para entender o papel da personagem na ação. Além disso, não mostrar Maria delatando David preserva a personagem, que mantém para o espectador a aparência de passividade e ingenuidade enquanto condena seu enteado à morte.

Em um seriado cujo tema - o narcotráfico - tende a remeter a um universo tradicionalmente masculino, cujos personagens, heróis e anti-heróis, são quase todos homens, a ação de Maria é importante, pois subverte a passividade associada ao gênero feminino, ainda que remeta a um gesto tipicamente masculino dentro das narco-narrativas: a vingança com violência. As personagens femininas de Narcos estão em grande medida submissas aos homens, sejam como amantes, esposas ou mães comportadas e compreensivas. Trata-se, efetivamente, de universo simbólico no qual a dominação masculina é quase inquebrantável. Maria, que nunca havia desempenhado nenhuma ação de importância narrativa na série, passa a ter influência fundamental no desenrolar final da história pois, se David estivesse vivo, ele assassinaria o contador Guillermo Pallomari e impediria o julgamento do Cartel de Cali nos EUA. Abre-se, assim, uma possibilidade de resistência feminina dentro da estrutura patriarcal representada pela temporada, ainda que o gesto de Maria, inevitável e ambiguamente, esteja conformado pelas regras dessa mesma estrutura, que ela sozinha não tem poder para alterar. Embora existam limites para a resistência feminina, Maria desloca-se muito bem no interior de um mundo dominado por homens, sobrevivendo como pode em meio à violência do narcotráfico, alternando entre a passividade que se espera de uma esposa submissa e a ação efetiva quando entra no modo-sobrevivência.

Nesse sentido, até a entrega da localização David, toda a trajetória de Maria na terceira temporada de Narcos remete ao que Bourdieu denomina "as armas dos fracos" na obra $A$ Dominação Masculina, ou seja, as armas disponíveis àqueles que estão submetidos ao universo masculino, tais como a sedução, por exemplo, que, "na medida em que se baseia em uma forma de reconhecimento da dominação, vem reforçar a relação estabelecida de dominação simbólica" (2017, p. 87). Bourdieu nos mostra que a sedução como arma tem sua lógica e sua eficácia em uma sociedade na qual o corpo feminino continua, mesmo depois de tantas décadas de luta feminista, "subordinado ao ponto de vista masculino" (2017, p. 49). As armas dos fracos, para Bourdieu, acabam corroborando os estereótipos referentes ao gênero feminino: a Maria só lhe resta se identificar com seu papel de mulher-troféu, aquele que the coube em um ambiente machista, violento e desigual no qual homens pobres ambiciosos tornam-se bandidos cruéis e mulheres pobres bonitas transformam-se em suas amantes. Por isso ela é chamada de puta e cadela em outros momentos do seriado, sempre se calando diante das ofensas e transformando-a em sobrevivência em um ambiente no qual o poder muda rapidamente de mãos. Quando decide se vingar de David, Maria muda suas armas, deixando de lado a sedução e assenhorando-se de um outro tipo de poder, mais prático, objetivo e efetivo, e que tem capacidade de alterar o estado de forças do universo masculino. 
Ao escrever sobre A Estrada Perdida (2017), de David Lynch, Slavoj Žižek (2009) faz uma análise da mulher no gênero noir e sua retomada nos anos 80 e $90 \mathrm{com}$ os filmes neonoir, dos quais O Poder da Sedução (1994) e Corpos Ardentes (1981) são exemplos. Segundo o autor, os filmes noir dos anos 40 e 50 expressam uma fantasia masculina em torno da femme fatale, a mulher atraente, manipuladora e sexualmente ativa que, ao final, precisa ser punida, de modo que a fantasia permaneça controlada e a realidade protegida de sua realização. O neonoir, ao contrário, permite que "a femme fatale triunfe e reduza o parceiro a um imbecil condenado a morrer" (2009, p. 129). Ela "subverte a fantasia masculina precisamente ao concretizá-la de maneira direta e brutal, ao transferi-la para a 'vida real'" (2009, p. 130-131). Em Narcos, estamos distantes do gênero noir e neonoir, ainda que próximos do gênero policial, mas podemos aproximar a ação de Maria à análise de Žižek no sentido de que se trata da extrapolação de certas fantasias masculinas sobre a mulher-troféu, sexualmente desejada e ao mesmo tempo menosprezada, pois considerada mera mercadoria que vive de vender seu corpo para sobreviver. Por isso a mulher-troféu deve permanecer controlada, comprada e dominada, já que os laços que a ligam a seus homens são puramente materiais. Ao entregar David, Maria ultrapassa a fantasia que a mantinha simbolicamente controlada, vendendo o que no momento tem de melhor: não seu corpo, mas informação. A Maria enquanto mulher-troféu representa a fantasia de uma mulher bela e passiva, que não questiona os desígnios de seu homem, mas a Maria que emerge do real é capaz de planejar friamente o assassinato de um homem quando vê suas condições de vida ameaçadas.

No universo de Narcos povoado de mulheres-mantidas, estrangeiras desinseridas, corpos que são suporte para a sedução masculina, esposas superficiais e algumas profissionais competentes, temos um conjunto de representações que, no geral, não nos parece fazer jus à contribuição feminina na sociedade. A despeito da estética de "bom gosto", pensada para o espectador contemporâneo internacional, consumidor de plataformas de streaming, exigente em relação à edição e à direção de arte, Narcos não consegue se afastar da heteronormatividade patriarcal que perpassa as narco-narrativas. Isso nos leva à questão abordada no início desse texto: ainda que produtos como Narcos procurem contrapor-se à estética considerada feminina da serialidade televisiva latino-americana - a telenovela -, bem como aos produtos dirigidos a homens menos sofisticados que desfrutam de cenas de violação e violência ligadas à criminalidade, eles são muito menos "universais" do que pretendem. Podem ser, inclusive, muito mais machistas do que uma telenovela, tendo em vista que o protagonismo é fortemente homem-orientado e os estereótipos femininos mais tradicionais são reproduzidos, enquanto a forma e a estética são construídas para parecerem elegantes e universais.

No entanto, a sequência da vingança de Maria nos sugere que a cultura de massas é, tanto na forma quanto no conteúdo, multidimensional, complexa, repleta de possibilidades de análise, que devemos estar abertos a considerar. O subalternizado pode emergir de lugares inesperados, justamente daqueles personagens - como Maria - que pareciam mais indefesos, menos perigosos e mais conformados. A passividade, Maria a utiliza como uma máscara. Os homens - sobretudo David e seus sicários - não conseguem enxergar através dela, presos que estão ao estereótipo aparente de mulher-troféu, e morrem por ser incapazes de ver o perigo que se esconde atrás mulher que eles mesmos objetificam. Como nos mostra Fredric Jameson (1994), "as obras de cultura de massa não podem ser ideológicas sem serem, em certo ponto e ao mesmo tempo, implícita ou explicitamente utópicas: não podem manipular a menos que ofereçam um grão genuíno de conteúdo, como paga ao público prestes a ser tão manipulado" (1994, p. 20).

\section{Referências}

ALMEIDA, Heloisa Buarque de. "Melodrama comercial: reflexões sobre a feminilização da telenovela". cadernos pagu, Campinas, n. 9, p. 171-194, 2002.

BAZIN, André. Qu’est-ce que le cinéma? Paris: Les Éditions du Cerf, 2002.

BELTING, Hans. La vraie image. Paris: Gallimard, 2007.

BERGER, John. Ways of seeing. London: Penguin Books, 2008.

BOURDIEU, Pierre. A dominação masculina. Rio de Janeiro: Best Bolso, 2017.

COLONNA, Vincent. L'Art des Séries Télé. Paris: Payot \& Rivages, 2015.

CONNELL, Robert William. Masculinities. Berkeley/Los Angeles: University of California Press, 2005.

GROSSI, Miriam Pillar. "Masculinidades: uma revisão teórica". Antropologia em primeira mão, Florianópolis, v. 75, n. 1, p. 5-37, 2004. 
HAMBURGER, Esther Império. "A expansão do 'feminino' no espaço público brasileiro: novelas de televisão nas décadas de 1970 e 80". Revista Estudos Feministas, Florianópolis, v. 15, n. 1, p. 153-175, janeiro/abril 2007.

JAMESON, Fredric. "Reificação e utopia na cultura de massa". Crítica marxista, v. 1, n. 1, p. 1-25, 1994.

JODELET, Denise. "Représentations sociales: un domaine en expansión”. In: JODELET, Denise (Org.). Les représentations sociales. Paris: Presses Universitaires de France, 1991. p. 31-61.

JODELET, Denise. Representações Sociais e Mundos da Vida. Curitiba: PUCPRESS, 2017.

JORGE, Marina Soler. "O cinema e a imagem verdadeira". ARS, São Paulo, v. 11, n. 22, p. 98-121, julho/dezembro 2013.

KIMMEL, Michael S. "A produção simultânea de masculinidades hegemônicas e subalternas". Horizontes Antropológicos, Porto Alegre, v. 4, n. 9, p. 103-117, outubro 1998.

LAURETIS, Teresa de. Technologies of Gender. Indiana: Indiana University Press, 1987.

MARTIN, Brett. Homens Difíceis. São Paulo: Aleph, 2014.

MARTINI, Nelson Minello. "Masculinidades: un concepto en construcción”. Nueva Antropología, Distrito Federal, México, v. 18, n. 61, p. 11-30, setembro 2002.

MARX, Karl; ENGELS, Friedrich. A ideologia alemã: crítica da mais recente filosofia alemã em seus representantes Feuerbach, B. Bauer e Stirner, e do socialismo alemão em seus diferentes profetas. São Paulo: Boitempo, 2015.

MEDRADO, Benedito; LYRA, Jorge. "Por uma matriz feminista de gênero para os estudos sobre homens e masculinidades". Revista Estudos Feministas, Florianópolis, v. 16, n. 3, p. 809-840, setembro/dezembro 2008.

MENEZES, Paulo. 'Problematizando a 'representação': fundamentos sociológicos da relação entre cinema, real e sociedade". In: RAMOS, Fernão; MOURÃO, Maria Dora; CATANI, Afrânio; GATTI, André Piero (Orgs.). Estudos de cinema SOCINE. Porto Alegre: Sulina, 2000. p. 333-348.

ORTIZ, Renato. Mundialização e Cultura. São Paulo: Brasiliense, 1994.

PETRO, Patrice. "Mass culture and the feminine: The 'place' of television in film studies". Cinema Journal, Austin, v. 25, n. 3, p. 5-21, abril/junho 1986.

RABENHORST, Eduardo Ramalho; CAMARGO, Raquel Peixoto do Amaral. "(Re)presentar: contribuições das teorias feministas à noção da representação". Revista Estudos Feministas, Florianópolis, v. 21, n. 3, p. 981-1000, setembro/dezembro 2013.

ŽlŽEK, Slavoj. Lacrimae rerum: ensaios sobre cinema moderno. São Paulo: Boitempo, 2009.

Marina Soler Jorge (marina.soler@unifesp.br) é socióloga e Professora Associada do Departamento de História da Arte da Escola de Filosofia, Letras e Ciências Humanas da Unifesp e do Programa de Mestrado em História da Arte da Unifesp. Cursou Sociologia e Ciência Política na Unicamp, é mestre em Sociologia pela Unicamp e Doutora em Sociologia pela USP. 


\section{COMO CITAR ESSE ARTIGO DE ACORDO COM AS NORMAS DA REVISTA}

JORGE, Marina Soler. "Mulheres em um mundo de homens: representação feminina em Narcos e a ilusão da ficção seriada 'universal"'. Revista Estudos Feministas, Florianópolis, v. 29, n. 1, e67486, 2021.

\section{CONTRIBUIÇĀO DE AUTORIA}

A versão original deste artigo foi traduzida para o inglês por Jeffrey Hoff - jeffhoff@floripa.com.br.

\section{FINANCIAMENTO}

Esse artigo é fruto de pesquisa desenvolvida com recursos da FAPESP - Fundação de Amparo à Pesquisa do Estado de São Paulo - sob a modalidade Auxílio Regular, Processo 2018/09435-3.

\section{CONSENTIMENTO DE USO DE IMAGEM}

Não se aplica.

\section{APROVAÇĀO DE COMITÊ DE ÉTICA EM PESQUISA}

Não se aplica.

\section{CONFLITO DE INTERESSES}

Não se aplica.

\section{LICENÇA DE USO}

Este artigo está licenciado sob a Licença Creative Commons CC-BY 4.0 International. Com essa licença você pode compartilhar, adaptar, criar para qualquer fim, desde que atribua a autoria da obra.

\section{HISTÓRICO}

Recebido em 09/09/2019

Reapresentado em14/04/2020

Reapresentado em 06/07/2020

Aprovado em 17/07/2020 